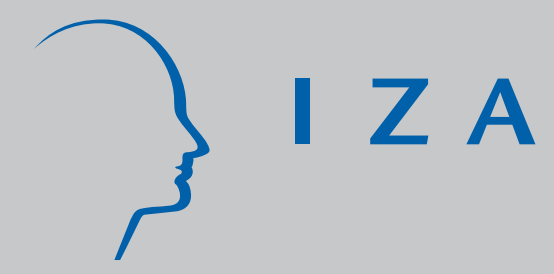

IZA DP No. 2469

Do Downward Private Transfers Enhance Maternal Labor Supply? Evidence from around Europe

Ralitza Dimova

François-Charles Wolff

November 2006 


\title{
Do Downward Private Transfers Enhance Maternal Labor Supply? Evidence from around Europe
}

\author{
Ralitza Dimova \\ Brunel University, \\ CNAV and IZA Bonn
François-Charles Wolff
LEN-CEBS, University of Nantes, CNAV and INED

Discussion Paper No. 2469

November 2006

\author{
IZA \\ P.O. Box 7240 \\ 53072 Bonn \\ Germany \\ Phone: +49-228-3894-0 \\ Fax: +49-228-3894-180 \\ E-mail: iza@iza.org
}

Any opinions expressed here are those of the author(s) and not those of the institute. Research disseminated by IZA may include views on policy, but the institute itself takes no institutional policy positions.

The Institute for the Study of Labor (IZA) in Bonn is a local and virtual international research center and a place of communication between science, politics and business. IZA is an independent nonprofit company supported by Deutsche Post World Net. The center is associated with the University of Bonn and offers a stimulating research environment through its research networks, research support, and visitors and doctoral programs. IZA engages in (i) original and internationally competitive research in all fields of labor economics, (ii) development of policy concepts, and (iii) dissemination of research results and concepts to the interested public.

IZA Discussion Papers often represent preliminary work and are circulated to encourage discussion. Citation of such a paper should account for its provisional character. A revised version may be available directly from the author. 
IZA Discussion Paper No. 2469

November 2006

\section{ABSTRACT}

\section{Do Downward Private Transfers Enhance Maternal Labor Supply? Evidence from around Europe}

Drawing on a theoretical model of downward private transfers with endogenous labor supply and recursive econometric models based on 2317 mother-daughter pairs from the 2003 SHARE data on 10 European countries, we investigate the impact of private transfers on the career choices of transfer-receiving young mothers. For Europe as a whole, we find a strong positive impact of grandchild care on the labor force participation decision of the mother, but no clear impact of either grandchild care or monetary transfers on the mother's degree of labor market involvement. The link between family transfers and labor supply exhibits an interesting pattern across institutional settings. Finally, while both recipients and donors with better endowments are more likely to participate in a monetary transaction, time transfers are such that mothers with lower level of human capital tend to assist the professional development of their better endowed daughters.

JEL Classification: D64, J13, J22

Keywords: $\quad$ grandchild care, labor participation, financial transfers

Corresponding author:

François-Charles Wolff

LEN-CEBS

Faculté des Sciences Économiques

Université de Nantes, BP 52231

Chemin de la Censive du Tertre

44322 Nantes Cedex 3

France

E-mail: wolff@sc-eco.univ-nantes.fr

\footnotetext{
* We would like to thank Claudine Attias-Donfut, Sumon Bhaumik, Nauro Campos, Philip Cohen, Jan Fidrmuc, André Masson, Judith Tress, and seminar participants at Brunel University, INSEE, the 8th European meeting of the Grandparents Network in Estonia and the Annual Conference of the Population Association America at Los Angeles for helpful comments and suggestions. Financial support from the RTN project on Grandparenting and Intergenerational Relations in Ageing European Societies is gratefully acknowledged. All remaining disclaimers apply.
} 


\section{1/Introduction}

During the past several decades, decreasing fertility rates and rising life expectancy turned the attention of economists towards several major implications of population ageing around the world. On the one hand, researchers forecasted the impact of a shrinking labor force on economic growth and the fiscal sustainability of the pay-as-you-go pension system. They proposed an increase in retirement age and phasing out of the public pension premium over time as solution to the economic challenges (see Börsch-Supan, 2001, Beetsma et alii, 2003). In an alternative, but related analytical framework, economists explored the impact of the rising demand for informal elderly care on the labor supply of the care provider. This impact was typically found to be significant and negative (Boaz and Muller, 1992, Ettner, 1995, 1996).

Despite the stylized negative impacts of female labor market participation on fertility and of institutional inflexibility on the balancing of motherhood and career ${ }^{1}$, significantly less attempt has been made to explore the impact of the complex gamut of downward intergenerational transfers on the career and childcare choices of the younger generation in the shrinking labor markets of the developed aging economies. The large body of research addressing the choice of childcare and work among mothers typically concentrates on the labor market implications of government induced monetary incentives, treating the availability of informal care as exogenously given (Gronau, 1973, Heckman, 1974, Blau and Robins, 1988). At the same time, the literature studying the impact of downward intergenerational transfers on the labor supply of young individuals has focused predominantly on consequences of downward monetary gifts such as human capital investment or work disincentives (Becker, 1974; Becker and Tomes, 1976; Ehrenberg and Sherman, 1987; Wolff, 2006).

To the best of our knowledge, the only microeconomic studies that address the impact of intergenerational solidarity on the choice between motherhood and work explore the link between intergenerational co-residence and the labor supply of young women (Ogawa and Ermisch, 1996, Sasaki, 2002). They find a positive impact of intergenerational co-residence on the labor supply of young female participants in the intergenerational exchange and interpret this result as indicative of a high correlation of co-residence and

\footnotetext{
${ }^{1}$ See for instance the special issue of the Journal of Labor Economics (1985).
} 
downward transfers and hence positive effect of the latter on the work effort of the recipient.

This leaves out of focus not only the potentially important implications of intergenerational solidarity in both co-residing and non-co-residing households, but also the qualitatively different implications of the receipts of monetary and time transfers. On the one hand, there is strong evidence to suggest that while intergenerational co-residence in countries such as those of Western Europe and the United States is decreasingly frequent, time services, especially in the form of grandchild care are non-decreasing and indeed on the rise (Tobio, 2001, Leira et alii, 2005). Even more importantly, failure to consider the possibility of substituting monetary for time transfers to children may have important implications from the point of view of economic performance. For instance, macrotheoretical evidence suggests that while time transfers increase the labor force participation of young people, monetary transfers decrease their work effort (Cardia and $\mathrm{Ng}, 1998$ ).

We provide further insight into the subject with the use of a simple theoretical model, linking informal child care and monetary transfers provided by a benevolent parent and the labor supply of a transfer-receiving child, and an empirical test of the hypotheses derived from the model with the use of a rich data set on 10 different European countries. The solution of the theoretical model leaves us with three reduced form equations of grandchild care, monetary gift provision and labor supply by the transfer-receiving child, where grandchild care and monetary gifts are endogenous in the labor supply equation of the child. We estimate this simultaneous recursive model with the use of maximum likelihood.

For Europe as a whole, we find a strong positive impact of grandchild care on the labor force participation decision of the mother, and no impact of either grandchild care or monetary transfers on the mother's degree of labor market involvement. However, the link between intergenerational transfers and labor supply exhibits an interesting pattern across family oriented institutions. Furthermore, while both recipients and donors with better endowments are more likely to participate in a monetary transaction, time transfers follow an intergenerational solidarity pattern, whereby mothers with lower level of human capital tend to assist the professional development of their better endowed daughters.

The contribution of this paper is twofold. First, we touch upon a rather unpopular dimension to the debate on inter-generational transfers and labor supply in ageing economies with a simple test of the hypothesis of efficient (micro-level) reallocation of 
resources across generations. Our null hypothesis is that members of each generation selfselect into an optimal equilibrium of household assistance and labor supply based on a set of human capital characteristics. Secondly, we benefit from the availability of comparable data for 10 different European countries to explore the effect of family related institutions on the choices made by individuals and households.

The remainder of the paper is organized as follows. In Section 2, we present a simple model of intergenerational transfers where an altruistic parent provides time-related resources to the child and the child's labor supply is endogenous. The solutions for the transfer and labor functions define a recursive, simultaneous equations model whose estimation strategy is presented in Section 3. The relationship between grandchild care, monetary transfers and labor supply is tested using the European SHARE data set described in some detail in section 4 . The results obtained through maximum likelihood estimation are discussed in Section 5. Finally, section 6 concludes.

\section{2/ A model of private transfers of time and money with endogenous labor supply}

We start our analysis with an intergenerational model of private transfers where parents help their children by providing grandchild care and financial gifts. To better understand the link between the receipt of parental help and the child's decision to undertake paid employment, we assume that the child's labor supply is endogenous. We begin with a description of the basic framework, after which we solve the sequential transfer game.

We assume that downward transfers are driven by altruism as opposed to strategic exchange behavior ${ }^{2}$. This strong assumption is based on the fact that an exchange-motivated grandchild care supply in the classical sense, whereby the donor provides a service in exchange for money as in Cox (1987) is unlikely. Such a service would induce a very low repayment on the part of the child. If not, the child would have opted for formal (instead of informal) child care services.

One could, of course, suggest a dynamic conceptual framework whereby the provision of current period downward transfers of time and money on the part of the parent is stimulated by the more complex exchange motive for repayment in terms of future supply of informal care or money to the elderly parent. However, the empirical literature has failed 
to find convincing evidence in support of exchange- motivated coexistence of upward and downward transfers of services and money (Laferrère and Wolff, 2006). To the extent to which our focus is on the present period impact of transfers on the labor supply of the recipient, and given that our data is only available for a single point in time, we believe a life cycle exchange conceptual framework to be unnecessary complicating ${ }^{3}$. Finally, given that we explore the behavior of women with children as opposed to prospective mothers, we also ignore the possibility that grandchild demand is a function of the demonstration effect, whereby the child's propensity to furnish parents with attention is conditional on the parents' example (Cox and Stark, 2005).

Our model consists of two actors, an adult child (say a daughter) who decides how many work hours to supply and a parent (say a mother) who helps her adult child with grandchild care and cash gift. The parent and the child are denoted by subscripts $p$ and $k$, respectively. We assume that both the parent and the child are represented by only one individual. In other words, we assume income pooling at the household level for both the parent and the child, and we neglect complex bargaining issues between spouses.

We consider the following two-stage game. In the first stage, the altruistic parent provides transfers, either grandchild care or money. In the second stage, conditional on the parental transfer decision, the child chooses the number of work hours. This recursive structure allows us to solve the model through backward induction. We begin by analyzing the child's labor supply decision provided that the parent makes transfers, after which we characterize the optimal pattern of parental transfers.

The child is characterized by a utility function $v\left(c_{k}, l_{k}\right)$, which depends on the level of private consumption $c_{k}$ and on the amount of leisure $l_{k}$. The level of satisfaction is increasing in both arguments, so that we have $v_{1}>0$ and $v_{2}>0$. We also assume that $v$ is continuous, twice differentiable and quasi-concave $\left(v_{11}<0, v_{22}<0\right)$.

There are two resource constraints for the child. First, the total amount of time (normalized to one) is devoted to hours of work $h_{k}$ and leisure $l_{k}$, but the child may also benefit from grandchild care $s$ : these care services extend the child's full amount of time, as

\footnotetext{
${ }^{2}$ For a recent survey on the motives for private transfers, see Laferrère and Wolff (2006).

3 This is especially relevant to the subsequent empirical analysis of West European economies marked by strong old age social security support and hence relatively low incidence of private upward transfers.
} 
she may spend additional time to other activities when being helped. Secondly, the child may receive a gift $T$, so that her total income is $w h_{k}+y_{k}+T$, where $w$ is the wage rate and $y_{k}$ is an exogenous non-labor income. In sum, the two constraints are $h_{k}+l_{k}=1+s$ and $c_{k}=w h_{k}+y_{k}+T$.

After making the appropriate substitutions, the child's problem amounts to :

$$
\max _{h_{k}} v\left(w h_{k}+y_{k}+T, 1+s-h_{k}\right)
$$

The corresponding first-order condition $\partial v / \partial h_{k}=0$ implies :

$$
w v_{1}-v_{2}=0
$$

In other words, the marginal gain of paid employment $w v_{1}$ is equal to the marginal disutility of work $v_{2}$ in equilibrium. From (2), the optimal labor supply function of the child can be expressed as:

$$
h_{k}=h_{k}\left(w, y_{k}, s, T\right)
$$

It is then straightforward to investigate the effects of the different exogenous variables on the optimal amount of labor supply. Specifically, we find that:

$$
\begin{aligned}
& \frac{d h_{k}}{d s}=-\frac{w v_{12}-v_{22}}{w^{2} v_{11}-w v_{12}-w v_{21}+v_{22}}>0 \\
& \frac{d h_{k}}{d T}=-\frac{w v_{11}-v_{21}}{w^{2} v_{11}-w v_{12}-w v_{21}+v_{22}}<0
\end{aligned}
$$

As the denominator is negative for a maximum and the utility function is concave, it follows that the effect of $s$ on $h_{k}$ is necessarily positive, at least under the reasonable assumption that $v_{12}>0$, i.e. a complementarity between $c_{k}$ and $l_{k}$ in the utility function. With more parental services, the child is able to spend more time on paid employment. At the same time, the cash gift has an opposite effect on the child's labor supply. Receiving more money reduces the child's incentives to have a paid job, due simply to an income effect.

Note that transfer money spent on formal child care can release the monetary constraint and hence provide a stimulus to a recipient, especially one in the lower part of the skill distribution for whom formal childcare costs have proved to be prohibitive, to opt for paid employment. However, the inability of providers of monetary as opposed to in-kind transfers to have full control over the choices made by the recipient make the theoretical 
modelling of this possibility difficult (Pollak, 1988) ${ }^{4}$. Hence, while our null hypothesis is that monetary transfers have a negative impact on the labor supply of the recipient, we leave this hypothesis open to an empirical rejection.

Let us now turn to the parental problem. We denote by $u\left(c_{p}, s\right)$ the parental utility function, which is increasing in private consumption $c_{p}$ and grandchild care $s$, i.e. $u_{1}>0$ and $u_{2}>0$. The latter assumption is based on the psychologically and anthropologically reasonable assumption that the parent enjoys spending time with the grandchildren. While we assume such intrinsic utility for the provision of grandchild care services, there is no joyof-giving motive in our model (Andreoni, 1990) ${ }^{5}$. Once again, the reason for this is our focus on the link between childcare and labor supply and the related direct and easier to account for impact of in-kind as opposed to monetary transfers on the behaviour of the recipient (Pollak, 1988). Monetary transfers therefore enter our model as nothing more than a substitute for time transfers in releasing the constraints faced by the recipient.

We assume that $u($.$) is continuous, twice differentiable, and quasi-concave, so that$ $u_{11}<0$ and $u_{22}<0$. Since the parent behaves as an altruist, she seeks to maximize the augmented utility function $u\left(c_{p}, s\right)+\beta_{p} v\left(c_{k}, l_{k}\right)$, where $\beta_{p}$ is the caring parameter. It indicates the strength of the altruistic feelings from the parent towards the child, and this parameter belongs to the closed interval [0;1], the zero value being the egoistic case.

The parent is endowed with a fixed income $y_{p}$, but making transfers is costly. While this is evident for the cash gift which directly reduces the available income, we also assume that caring for the grandchildren is costly. For instance, even aside from accounting for the opportunity cost of foregone employment, visiting the grandchild (who does not necessarily live in the same dwelling) entails some distance related costs. Let $p$ be the price per unit of services, which is an increasing function of the geographic distance between the child and the parent. Then, the budget constraint for the parent is :

$$
c_{p}=y_{p}-T-p s
$$

\footnotetext{
4 And indeed for the subsequent empirical analysis, we have no information on the specific use a monetary transfer received has been put into.

5 This would be the case with the cash gift as a direct argument of the parental utility function.
} 
Recalling that $h_{k}$ is a function of $s$ and $T$ according to (3), the maximization program for the parent becomes:

$$
\begin{aligned}
& \max _{s, T} u\left(y_{p}-T-p s, s\right)+\beta_{p} v\left(w h_{k}+y_{k}+T, 1+s-h_{k}\right) \\
& \text { s.t. } h_{k}=h_{k}(s, T)
\end{aligned}
$$

Hence, the first-order conditions which give the optimal transfer values are :

$$
\begin{aligned}
& -p u_{1}+u_{2}+\beta_{p}\left(w h_{k 1} v_{1}-h_{k 1} v_{2}+v_{2}\right)=0 \\
& -u_{1}+\beta_{p} v_{1}+\beta_{p}\left(w h_{k 2} v_{1}-h_{k 2} v_{2}\right)=0
\end{aligned}
$$

with $h_{k 1}=\partial h_{k} / \partial s$ and $h_{k 2}=\partial h_{k} / \partial T$. At first sight, these conditions seem difficult to interpret. Fortunately, they can be simplified using (2), i.e. $w v_{1}-v_{2}=0$. This gives:

$$
\begin{aligned}
& -p u_{1}+u_{2}+\beta_{p} v_{2}=0 \\
& -u_{1}+\beta_{p} v_{1}=0
\end{aligned}
$$

The interpretation of (10) and (11) is now straightforward. According to (10), the cost for the parent to care for the grandchildren (owing to the price of those services) is equal to the sum of the selfish benefit $u_{2}$ and the altruistic gain $\beta_{p} v_{2}$ given by the increase in the child's level of well-being. According to (11), the marginal utility lost of transferring money to the child (owing to a lower income) is equal to the child's marginal utility of receiving money ${ }^{6}$. Combining (10) and (11) leads to :

$$
u_{2} / p+\beta_{p} v_{2} / p=\beta_{p} v_{1}
$$

meaning that, for the child, the marginal benefit of receiving money is equal to the marginal benefit of receiving grandchild care. When this equality does not hold, a better outcome can be reached by reallocating parental resources between grandchild care and cash gifts. Finally, we deduce that the optimal transfer functions for the parent are given by:

$$
\begin{aligned}
& s=s\left(w, p, \beta_{p}, y_{p}, y_{k}\right) \\
& T=T\left(w, p, \beta_{p}, y_{p}, y_{k}\right)
\end{aligned}
$$

which indicates how the respective incomes of the parent and the child influence the provision of services. In this model where an altruistic parent commits to transfer values which the child takes as given, we find that both type of transfers are endogenous in the

\footnotetext{
${ }^{6}$ Interestingly, this standard first-order condition which links the parent's and child's marginal utility of consumption also holds in the basic altruistic model (Laferrère and Wolff, 2006).
} 
child's labor force participation equation. From an empirical perspective, it means that the grandchild care, cash gift and labor supply equations have to be jointly estimated as these three equations define a recursive, simultaneous equations model. We now turn to the methodology used in estimating the parameters of the corresponding structural equations.

\section{3/ Econometric methodology}

In our empirical part, we do not attempt to estimate the structural model associated with our theoretical framework, as the choice of a specific utility function would certainly drive the empirical results. We rely instead on a simultaneous-equations model with latent variables (Heckman, 1978, Maddala, 1983). This allows us to account for the endogeneity of both the financial and time transfers in the child's labor supply equation. The econometric model includes three equations.

The first two equations are related to the different parental transfers. Following equation (13) and (14), we can express both the financial gift and grandchild care transfer as a function of several different exogenous characteristics. Let $s^{*}$ and $T^{*}$ be two latent variables indicating the propensity of the parent to provide respectively grandchild care and cash gift, $s^{*}$ and $T^{*}$ being either positive or negative. The two transfer equations are:

$$
\begin{aligned}
& s^{*}=X_{s} \beta_{s}+\varepsilon_{s} \\
& T^{*}=X_{T} \beta_{T}+\varepsilon_{T}
\end{aligned}
$$

where $X_{s}$ and $X_{T}$ are two sets of variables explaining respectively the grandchild care and financial gift outcomes, $\beta_{s}$ and $\beta_{T}$ are the vectors of associated parameters, and $\varepsilon_{s}$ and $\varepsilon_{T}$ are two random term errors which are normally distributed. Importantly, these two error terms may be correlated.

By definition, the two latent variables $s^{*}$ and $T^{*}$ are not observed from the data, but we have some information on the observed counterpart of the transfer variables. Unfortunately, owing to limitations with the data, we restrict our attention to the discrete decisions of giving for the parent, which are denoted by $S$ and $T$, respectively. Let $S=1$ when the parent provides grandchild care and $T=1$ when the parent gives money to the child. Then, we have : 


$$
\begin{gathered}
s=\left\{\begin{array}{lll}
1 & \text { if } & s^{*}>0 \\
0 & \text { if } & s^{*} \leq 0
\end{array}\right. \\
T=\left\{\begin{array}{lll}
1 & \text { if } & T^{*}>0 \\
0 & \text { if } & T^{*} \leq 0
\end{array}\right.
\end{gathered}
$$

To be consistent with the theoretical framework, the third equation indicates that the child's latent labor supply $h^{*}$ depends on a set of exogenous covariates and on the observed parental transfer $S$ and $T$. The labor equation can be formalized as :

$$
h^{*}=X_{h} \beta_{h}+\gamma_{s} s+\gamma_{T} T+\varepsilon_{h}
$$

where $X_{h}$ is a set of variables that explain the work decision, $\beta_{h}$ is the corresponding vector of parameters, and $\varepsilon_{h}$ is a normally distributed error term. The estimates of special interest for our analysis are both $\gamma_{S}$ and $\gamma_{T}$, which pick up the effect of informal grandchild care and cash gift on labor supply of the child. Again, the latent variable $h^{*}$ is not observed. As there is no information on the number of worked hours in the survey, we focus in what follows on the discrete decision of working for the child. Let $h=1$ when the child works, and $h=0$ otherwise, such that:

$$
h=\left\{\begin{array}{lll}
1 & \text { if } & h^{*}>0 \\
0 & \text { if } & h^{*} \leq 0
\end{array}\right.
$$

Clearly, equations (15)-(20) define a simultaneous model of equations which comprises one Probit equation for the labor decision and two Probit equations for the different transfer decisions. The endogeneity bias stems from the potential correlation between the random residual $\varepsilon_{H}$ and the error terms $\varepsilon_{s}$ and $\varepsilon_{T}$. While several studies have controlled for the potential endogenity bias using a two-stage estimate for discrete models (Ettner, 2002, Sasaki, 2002), we rely on a full maximum method estimation which avoids any efficiency loss.

The above framework can easily be estimated by maximizing the corresponding log likelihood. We denote by $\rho_{s T}, \rho_{s h}$, and $\rho_{T h}$ the respective coefficients of correlation between $\varepsilon_{s}$ and $\varepsilon_{T}, \varepsilon_{s}$ and $\varepsilon_{h}$ and $\varepsilon_{T}$ and $\varepsilon_{h}$. We assume that the residuals $\left(\varepsilon_{s}, \varepsilon_{T}, \varepsilon_{h}\right)$ follow a trivariate normal distribution such that $\left(\varepsilon_{s}, \varepsilon_{T}, \varepsilon_{h}\right) \sim N\left(0,0,0,1,1,1, \rho_{s T}, \rho_{s h}, \rho_{T h}\right)$. Given the definition of $s, T$ and $h$, it is straightforward to model explicitly the individual 
contribution to the log likelihood. There are eight groups for the different observations as each dependent variable is equal either to 0 or 1 , and the probability of being in each group may be expressed as a function of the trivariate normal distribution function ${ }^{7}$.

Given our data-based ability to distinguish between full time and part time labor supply, we explore as an additional case the impact of parental transfers on the child's choice between full time work, part time work and no work. In that case, the dependent variable $h$ takes the following values: $h=0$ if the child does not work, $h=1$ if the child works part time, and $h=2$ if the child works full time. The model now comprises two Probit equations for the grandchild care and cash gift transfers, and one ordered Probit equation for the labor participation. Things are slightly more difficult for the computation of the likelihood, due to to the threshold level to estimate. Again, we rely on a maximum likelihood method to estimate the corresponding model.

An additional concern is the direction of the bias related to the endogeneity of the transfer variables in the labor participation equation. This bias is difficult to determine a priori. Let us consider for instance the case of grandchild care. On the one hand, it is reasonable to expect a positive correlation between the random terms $\varepsilon_{H}$ and $\varepsilon_{s}$ as higher propensity for grandchild care on the part of the parent increases the child's time available for paid work. At the same time, the receipt of informal care may also require a higher taste for family involvement and leisure, implying a negative correlation between the residuals. Thus, knowing how the correction of the endogeneity problem affects the magnitude of the coefficients $\gamma_{S}$ and $\gamma_{T}$ in the labor equation remains an empirical question.

\section{4/ Data}

To estimate the relationship between downward transfers and labor participation, we make use of data from the first release of the SHARE data base. This data base contains detailed information on the financial, human capital, family and health status of elderly citizens of more than 50 years of age for 10 different European countries ${ }^{8}$. Clearly, the transfer providing parent is the primary respondent to the SHARE questionnaire.

\footnotetext{
${ }^{7}$ When performing the estimation, we rely on a numerical integration process which allows to speed up the computation process.

${ }^{8}$ For further information and download of the data, see the following url http: \\www.share-project.org. The countries included in the First, 2003, release of SHARE are Austria, Germany, Netherlands, Sweden, Spain, Italy, Denmark, France, Greece and Switzerland.
} 
However, aside from detailed information on that primary respondent, the data base also contains some information on up to four randomly selected respondent's children. This latter information includes not only human capital characteristics, but also number of children, age of the youngest and eldest child, and labor force participation. Although information on the actual number of hours of work supplied by the child is missing, we are able to distinguish between different levels of labor force involvement, such as full time work, part time work and no work, which provides sufficient grounds for analyzing the impact of transfers on the degree of labor market involvement of the recipient.

Our data set has several interesting intergenerational transfer related features. To begin with, when the data set was compiled, only one member of each elderly household gave response to questions related to the provision of grandchild care and monetary transfers and the respective response was repeated in the column related to the spouse of that respondent. In other words, the data compiling methodology is consistent with the assumption of pooling of resources within the elderly households. Secondly, while we do have information on the characteristics of both biological and non-biological children of the elderly respondents, information on the characteristics of sons and daughters in-law is absent.

The economics literature gives us little guideline on how to overcome this shortcoming of the data. While there are several studies on both upward and downward financial transfers (see Arrondel and Masson, 2006, Laferrère and Wolff, 2006) as well as upward services in the form of informal care for disabled elderly parents (Ettner, 1995, Pezzin and Schone, 2002), economic studies on the grandchild care are virtually absent. However, the bulk of the sociological literature indicates that not only grandmothers, as opposed to grandfathers, are the primary suppliers of grandchild care but also grandchild care supply is more likely to affect the career prospects of the grandchild's mother rather than the father (Tobio, 2001). Moreover, sociological evidence indicates that it is the maternal grandmother who tends to be the primary supplier of grandchild care in Europe (Tobio, 2001, Herlyn, 2001, Dench and Ogg, 2001, 2002) ${ }^{10}$.

\footnotetext{
${ }^{9}$ In Spain, for instance, $27 \%$ of the female participants in a representative survey point out their own mother as a primary provider of help in their struggle to balance work and family life, ahead of even their husband or partner $(25 \%)$, proximity to work $(11 \%)$ or other family members $(10 \%)$.

${ }^{10}$ In Spain, in services such as taking the grandchild to school, it is the maternal grandmother that faces the highest probability of providing support (19\% of the cases), followed by the maternal grandfather $(11 \%$ of the cases), the paternal grandmother ( $9 \%$ of the cases) and the paternal grandfather (5\% of the cases). In Germany,
} 
Hence, we overcome the limitations of our data, by justifiably restricting our sample to elderly mothers and their adult daughters who have at least one child. We further restrict our sample to the relevant cases of daughters in working age and grandchildren young enough to need care. Given the evidence of highest amount of grandchild care supply being provided to children younger than 10 years of age, we treat this age as our upper bound (Heckman, 1974, Tobio, 2001). Our final sample contains 2317 observations.

\subsection{Descriptive statistics}

In our theoretical section, we derived three reduced form equations of time, monetary transfers and labor supply. In keeping with the stylized literature on private transfers and labor supply, the time and monetary transfers are a function of the income levels of the donor and recipient, the wage rate of the recipient, the caring parameter and the opportunity cost of the donor, while labor supply is function of the wage rate, non-labor income and endogenous time and monetary transfers.

Our monetary transfer variable takes the value of one if, during the reference period, the respondent has provided a monetary transfer of 250 or more euros to any of her children. We can also distinguish between infrequent grandchild care (grandchild care provided on less than a weekly basis), frequent grandchild care (care provided on a daily or weekly basis) and no grandchild care during the same reference period. Since experimentation with the data indicated that only frequent grandchild care has significant influence on the labor supply of the recipient, in our analytical part we use a grandchild care variable taking the value of one if the donor provides grandchild care on a daily or weekly basis. As indicated earlier, we define two different dependent variables for our labor supply equation: (i) a variable taking the value of one if the transfer recipient provides any labor supply, and (ii) a variable taking the value of zero if the recipient does not participate in the labor market, a value of one if she participates on a part time basis, and a value of two if she works full time.

According to our theoretical model, the main exogenous variables are the income levels on both the donor and the recipient and the wage rate faced by the donor. The data set makes available continuous variables of the total current and asset household income of 
the donor and we use this variable as a proxy for the parent's income. Unfortunately, we do not have information on the income of the recipient, but we assume it to be highly correlated with human capital and household level characteristics such as age, education, marital status, number of children and age of the youngest child. We therefore include these variables directly into the transfer and labor supply equations. Our further education variable is comparable across the different countries and takes a value of one if the recipient of transfers has tertiary education. Experimentation showed a linear impact of the donor's age on labor supply and we therefore do not account for nonlinearities in our subsequent empirical estimation.

One of the major shortcomings of the data is the lack of information on wages. However, as indicated by Ettner (1996), empirical construction of wage rates for nonworkers involves issues of identification. We therefore follow the broader empirical literature in including factors influencing the wage (such as age or education) directly in our structural equation as a proxy for the potential wage rate.

In addition to these main independent variables, we include in our transfer equations controls for the geographical distance between donors and recipients, health, marital status and number of children of the donor, as well as a dummy variable taking the value of one if the donor herself receives a transfers. We distinguish between residence in the same building or across the street, geographical distance larger than this but smaller than $25 \mathrm{~km}$, distance between 25 and $100 \mathrm{~km}$ and distance larger than $100 \mathrm{~km}$. Our health variable takes the value of one if the respondent reports less than two chronic diseases. Aside from capturing the opportunity cost of the transfer, these variables serve as excluding conditions in our simultaneous system of equations.

Table 1 highlights the descriptive statistics for four different combinations of intergenerational transfers: (i) monetary transfer and no grandchild care, (ii) grandchild care and no monetary transfer, (iii) monetary transfer and grandchild care and (iv) neither monetary transfer nor grandchild care. While the age of the recipient of transfers does not vary significantly across the categories, we do observe that better educated recipients are more likely to receive a monetary rather than a time transfer ${ }^{11}$. In other words, parents with

maternal lineage is found to be reinforced by increasing number of divorces.

11 The mean of further education exceeds $0.75-0.80$ in the case of monetary receipt whether simultaneously with a time transfer or without a time transfer, the mean of further education ranges around 0.60 among mothers not receiving monetary transfers. 
better endowments are in a better position to provide a monetary instead of time support to their educated children. This hypothesis is confirmed by the higher mean of further education among providers of monetary transfers than among providers of time transfers, as well as the higher mean of current income among providers of monetary as opposed to providers of time transfers.

\section{Insert Table 1 about here}

Expectedly, our statistics also indicate that the acts of not donating and not receiving any transfers are increasing functions in the number of children of the donor and recipient and the age of the grandchild and a decreasing function of the good health condition of the provider of transfers. In addition, the provision of time related assistance decreases steeply with the increase in geographical distance between the donor and the recipient. Finally, we observe some transmissibility of transfer behavior in that donors who themselves receive transfers are more likely to provide transfers.

Table 2 highlights the characteristics of the recipients of transfers by employment status, namely full time employment, part time employment and not working. Expectedly, better educated and more experienced mothers are more likely to hold full time employment, while low level of education has a strong influence on non-employment. At the same time, the degree of employment (full-time versus part time) is a negative function of the number of young children and a positive function of the age of the child. Married mothers are slightly more likely to not work than to work, indicating at least a weak impact of double earnings on labor force participation among women with children. Finally, the provision of frequent grandchild care for our sample as a whole appears to stimulate the labor force participation of the recipient, while monetary transfers tend to discourage full time labor force participation.

\section{Insert Table 2 about here}

Overall, our preliminary descriptive analysis is consistent with our theoretical model and conceptual priors. We do observe for the sample as a whole that time transfers encourage the labor force participation of the recipient, while monetary transfers discourage it. The rest of our descriptive analysis is also in conformity with expectations. Higher degree of human capital of the mother is associated with both a higher level of labor market participation and higher probability of receipt of monetary as opposed to time transfers. At the same time, donors with better human capital characteristics are more likely to donate 
monetary as opposed to time transfers. Finally, higher level of family involvement, captured by larger number of children and lower age of the youngest child discourages not only labor force participation, but also the receipt and donation of transfers.

We will use these priors as a starting point for our empirical estimations, where we take a step away from simple correlations by correcting for the obvious endogeneity of intergenerational transfers in the labor force participation equation of the recipient.

\subsection{Cross-country differences in transfers and labor supply}

Before proceeding with the test of our hypotheses, it is worthwhile devoting some attention to the possible cross-country differences in transfers and labor supply. The availability of 2317 observations for a total of 10 countries makes individual country analyses econometrically difficult, while introducing 9 country variables reduces the degrees of freedom and makes interpretation of the numerous country characteristics that these dummies may stand for difficult to interpret.

We therefore opt for the allocation of countries in different groups based on comparable institutional characteristics. Our first choice was to use indexes of labor market characteristics, such as labor market flexibility and labor market related social security legislation (Botero et alii, 2003), as well as indexes capturing the difference in family related policies such as cash benefits to parents, duration of maternity and childcare leave and other support to working parents (Gauthier, 2002). However, high level of correlation across the diverse indexes made their use in our empirical analysis unfeasible. Hence, we give preference to the alternative strategy of classification of countries in stylized social security regimes, defined primarily on the basis of family policy differences (Gautier, 2002) ${ }^{12}$.

12 This typology stems from the stylized classification of countries according to social security regimes (EspingAndersen, 1990; 1994), which has faced a lot of criticisms (e.g. Castles and Mitchell, 1993; Liebfried, 1992; Sainsbury, 1994; Gordon, 1990; Orloff, 1993), but has nevertheless remained one of the most influential reference point in institutional studies exploring welfare state dynamics. With the use of one of its latest modifications, we benefit from (i) including a South-European regime, marked by specific family based characteristics as a separate category and (ii) using family related policies, the primary focal point of our analysis as a basis for country classification. This overlooks the possibility that old age security characteristics might influence the behavior of the elderly providers of transfers. However, the insignificant differences across old age security regimes across the countries in our sample (institutionalized retirement age in all but one of the countries being 65 , etc.) make the omission immaterial in our context. Indeed, experimentation with both alternative old age security indexes and welfare state classification including the original Esping-Andersen welfare state typology did not change the message of our research and we adopted the Gauthier (2002) version as the optimal choice in capturing the relevant cross-country institutional context in our analysis. For further details, see the references included in this footnote. 
We proceed as follows. The countries in our sample are allocated into four different categories on the basis of family policies including both cash and time oriented government assistance to working and non-working parents. Our social democratic category, including Sweden and Denmark, is characterized by both high level of cash support and time related government assistance in terms of childcare leaves, relatively inexpensive childcare facilities and flexible employment patterns. In the category conservative regime, we include Austria, France, Germany and Netherlands. This system is similar to the social democratic system in terms of cash support to parents and relatively long childcare leaves, but suffers from limited childcare facilities.

While both the social security and the conservative and the social democratic system are marked by generous family policies, the latter being more generous than the former, the liberal (including Switzerland in our sample) and the southern European regimes (including Spain, Italy and Greece) stand at the other end of the generosity spectrum. These regimes are characterized by low levels of both cash and time related childcare facilities, the main difference in the former compared to the latter being the higher level of support for families in need combined with economic philosophy giving higher credence to market forces.

Figure 1 highlights the distribution of grandchild care across the different regimes. We define three different categories of grandchild care: (i) regular care on a daily or weekly basis, (ii) irregular care of less than weekly basis and (iii) no grandchild care at all. Expectedly, we observe significantly higher level of regular grandchild care provision among the liberal and southern European regimes, characterized by scarce childcare facilities. However, we do observe a higher level of irregular grandchild care provision among the more generous social-democratic and conservative regimes, perhaps on account of altruistic feelings on the part of the grandparents.

\section{Insert Figure 1 here}

Figure 2 highlights the distribution of the alternative monetary transfers across institutional settings. While the difference in the provision of these transfers is both of a smaller scale and more similar across the institutional settings, we do observe a higher incidence of such transfers in the most generous social democratic regime than in the least generous south European regime. As these two regimes stand at two extremes in terms of time transfers, this observation does provide some evidence that institutional characteristics might influence the substitution of different types of transfers by the parents. 


\section{Insert Figure 2 bere}

As the main focus of this paper is the impact of transfers on labor supply, as a next step in our preliminary data analysis, we graph the distribution of employment across institutional settings. Figure 3 highlights the distribution of labor force participation across full time, part time and no work activities of the daughter. The observed differences across institutions are once again interesting.

\section{Insert Figure 3 bere}

While the most generous in terms of family policies social democratic regime is characterized by the highest level of labor market involvement of women with children, the most market oriented liberal regime accounts for the least level of full time employment. At the same time, we observe a clear dichotomy of high level of non-working and high level of full time employment among south European economies, possibly on account of low level of choices related to flexible participation in the labor market (Gerhard et alii, 2005). In other words, we do observe significant differences in both transfers and labor supply across institutional settings and therefore find it essential to control for these differences in our subsequent analysis.

\section{5/ Econometric results}

In Table 3 and 4, we report the maximum likelihood estimates of the simultaneous recursive model. We start with an estimation of a simultaneous system of three Probit equations for labor force participation, regular grandchild care and monetary transfers, and then proceed to accounting for the possibility of different degrees of labor market involvement by estimating a simultaneous system of equations including an ordered Probit model of labor force participation (including full-time, part-time employment and nonemployment), a Probit model for regular grandchild care and a Probit model of monetary transfers. Column 1 in each table reports the results from labor supply equation, after accounting for the endogenous provision of grandchild care and monetary transfers. In Column 2, we report the results from our grandchild care equation. Finally, in Column 3, we report the estimates from our monetary transfer equations.

\section{Insert Table 3 here}

Let us focus on the impact of the transfer variables. The coefficient of the endogenously treated grandchild care variable in the labor participation estimates reported in 
Table 3 is 0.436 , significant at the $5 \%$ level, while the coefficient of our endogenous monetary transfer variable is also positive and of a similar dimension, but not significant. In other words, our results indicate that for the sample as a whole, grandchild care has a positive impact on the labor force participation of young mothers, while monetary transfers have no impact on the mother's labor force participation.

Our results further indicate that social democratic institutions involve a higher level of labor force participation and liberal institutions involve a lower level of labor force participation than the omitted southern European category, an observation consistent with the pattern highlighted in Figure 3. The rest of labor participation estimates are consistent with our priors. Specifically, we observe that higher level of human capital, captured by further education and age/experience have positive impact on labor force participation, while higher level of household involvement, captured by the number of children and lower age of the youngest child, have a negative influence on the labor force participation of the mother.

Interestingly, the results reported in column 2 of Table 3 indicate that higher education of the donor has a negative influence on the provision of grandchild care, while a higher education of the recipient has a positive influence on the provision of grandchild care. In other words, we observe an intergenerational solidarity pattern whereby mothers with lower human capital promote the professional development of their better educated daughters, an observation consistent with the sociological literature (see also Gerhard et alii, 2005). The grandchild care estimates are also consistent with our priors in that larger number of grandchildren and children has negative impact on the provision of grandchild care. In addition, we find further confirmation of the transfer transmission hypothesis whereby grandparents having received transfers are more likely to provide help themselves (Arrondel and Masson, 2006). Finally, we find a negative impact of social democratic and conservative institutions on the provision of grandchild care, an observation which is once again consistent with the pattern observed in our graphs.

There is no obvious impact of family related institutions on the provision of monetary transfers. Specifically, none of the coefficients of our institutional variables reported in Column 3 of Table 3 is significant, indicating that unlike time transfers monetary transfers are perhaps driven to a higher extent by the needs of the recipient and the financial ability of the donor. This latter hypothesis is confirmed by the observation of a strong and 
positive impact of both current earnings and financial assets of the donor on the provision of monetary transfers. Better educated children are once again more likely to receive transfers than less educated children, while transfers are a decreasing function of the number of children of the donor.

We now proceed to assessing the results from our ordered Probit model of labor supply, after accounting for the endogeneity of time and monetary transfers. The estimates highlighted in Column 1 of Table 4 indicate that neither time, nor monetary transfers have any impact on the degree of labor market involvement of the mother.

\section{Insert Table 4 bere}

Furthermore, we observe a change in the coefficient of the conservative regime variable vis-à-vis the omitted southern European variable. In particular, while there is no statistically significant difference between the conservative regime and the omitted southern European category in the labor participation (Probit) equation, the coefficient of the conservative regime in the ordered Probit equation is significant and negative. This observation, consistent with the pattern highlighted in Figure 3, indicates a higher preference for part time as opposed to full time employment among mothers in the conservative regime category.

The rest of the estimates reported in Table 4 are consistent with those based on the system of three Probit equations. Once again, we observe a lower level of grandchild care provision in the case of the conservative and social democratic regimes compared to the omitted southern European category. Also, the impact of institutions on monetary transfers is insignificant. Mothers with lower endowments provide time assistance to daughters with lower endowments, while better off parents are more likely to provide a monetary assistance to their adult daughters. Increasing geographical distance has negative impact on the provision of grandchild care. Better human capital characteristics and lower level of family involvement (reflected in family size and youngest child's age) have positive impact on not only the decision to participate in the labor market, but also on the degree of labor market involvement and the probability of receiving any type of assistance from parents.

Overall, our empirical results are consistent with our theoretical predictions and reflect an efficient intergenerational and labor market participation environment. Specifically, we observe that higher level of human capital is the driving force behind the receipt of assistance. Parents tend to support their better off as opposed to weaker children and it is 
the stronger children that benefit from higher level of labor market involvement. Indeed, not only are endowments the driving force behind monetary transfers, but also mothers with lower endowments enter an intergenerational solidarity pattern by providing time assistance to their better off daughters.

Finally, we do find that family related institutions do have an impact on both intergenerational transfers and labor supply in that we observe a higher level of grandchild care supply in the least generous in terms of institutionalized assistance regimes. At the same time, family related institutions are found to be far from being the most important determinant of the choices between options such as motherhood, informal assistance and career, especially in so far as the choice between full time and part time work is concerned.

\section{6/ Concluding comments}

During the past several decades, much of the political economic debate related to the problems of ageing societies concentrated on the fiscal and informal care burden of the elderly population and on the productivity decreasing impact of the latter. Meanwhile, fertility and child related economic research focused almost exclusively on the impact of family related policies on the choices between motherhood and career, either ignoring or treating as exogenous informal care provision. Based on both stylized facts and sociological evidence, we postulated that this approach to the fertility and ageing related problems of developed economies is overly restrictive and proposed a theoretical model and empirical estimates of the reduced form equations emanating from the model to fill the potentially important gaps in the literature.

Specifically, we consider a simple theoretical model, linking informal child care and/or monetary transfers provided by a benevolent parent and the labor supply of a transfer-receiving child, and an empirical test of the hypotheses derived from the model with the use of a rich data set on 10 different European countries. The solution of the theoretical model leaves us with three reduced form equations of grandchild care, monetary gift provision and labor supply by the transfer-receiving child, where grandchild care and monetary gifts are endogenous in the labor supply equation of the child. We estimate this simultaneous recursive model with the use of maximum likelihood techniques.

Overall, our empirical results are consistent with our theoretical predictions and reflect an efficient intergenerational and labor market participation environment. Specifically, 
we observe that higher level of human capital is the driving force behind the receipt of assistance. Parents support their better off as opposed to weaker children and it is the stronger children that benefit from higher level of labor market involvement. Indeed, not only are endowments the driving force behind monetary transfers, but also mothers with lower endowments enter an intergenerational solidarity pattern by providing time assistance to their better off daughters. Finally, we find that family related institutions have an impact on both intergenerational transfers and labor supply in that we observe a higher level of grandchild care supply in the least generous in terms of institutionalized assistance regimes. However, they are far from being a major determinant of choices such as the degree of labor market involvement of young mothers.

In other words, our study not only opens a new dimension to the debate related to intergenerational transfers in ageing economies by taking a step away from the productivity deteriorating impact of informal elderly care, but also suggests that factors other than family institutions may be an important determinant of young women's choices between motherhood and career. 


\section{References}

Andreoni J., (1990), 'Impure altruism and donations to public goods: A theory of warm-glow giving', Economic Journal, vol. 100, pp. 464-477.

Arrondel L., Masson A., (2006), 'Altruism, exchange or indirect reciprocity: What do the data on family transfers show ?', in S.C. Kolm, J. Mercier Ythier, (eds), Handbook on the Economics of Giving, Reciprocity and Altruism, North-Holland, Elsevier.

Beetsma B., Broer P., (2003), 'The budgeting and economic consequences of ageing in the Netherlands,' Economic Modeling, vol. 20, pp. 987-1013.

Becker G., (1974), 'A theory of social interactions', Journal of Political Economy, pp. 1063-93.

Becker G., Tomes N., (1976), 'Child endowments and the quantity and quality of children', Journal of Political Economy, pp. S143-162.

Blau D., Robins P., (1988), 'Child-care costs and family labor supply', Review of Economics and Statistics, vol. 70, pp. 374-81.

Boaz R.F., Muller C.F., (1992), 'Paid work and unpaid help by caregivers of the disabled and frail elders', Medical Care, vol. 30, pp. 149-158.

Börsch-Supan A., (2001), 'Labor market consequences of population ageing', NBER Working Paper, n 8640 .

Botero J., Djankov S., LaPorta R., Lopez-de-Salines F., Shleifer A., (2003), 'The regulation of labor', NBER Working Paper, $\mathrm{n}^{\circ} 9756$.

Cardia E., Ng S., (1998), 'Intergenerational transmission of time and childcare', Review of Economic Dynamics, pp. 431-454.

Castles F.G., Mitchell D., (1993), 'Worlds of welfare and families of nations', in F.G. Castles (ed), Families of Nations, Patterns of Public Policies in Western Democracies, Aldershot, Dartmouth.

Cox D., (1987), 'Motives for private income transfers', Journal of Political Economy, vol. 95, pp. 508-46.

Cox D., Stark O., (2005), 'On the demand for grandchildren : Tied transfers and the demonstration effect', Journal of Public Economics, vol. 89, pp. 1665-1697.

Dench G., Ogg J., (2001), 'Grands-parents par la fille, grands-parents par le fils', in C. AttiasDonfut, M. Segalen (eds), Le siècle des grands-parents. Une génération phare, ici et ailleurs, Editions Autrement, Paris.

Dench G., Ogg J., (2002) Grandparenting in Britain. Institute of Community Studies, Great Britain.

Ehrenberg R., Sherman D., (1987), 'Employment while in college, academic achievement, and postgraduate outcomes: A summary of results', Journal of Human Resources, vol. 22, pp. $1-23$.

Ermisch J.F., Ogawa N., (1996), 'Family structure, home time demands and the employment patterns of Japanese married women', Journal of Labor Economics, vol. 14, pp. 677-702.

Esping-Andersen G., (1990), The Three Worlds of Welfare Capitalism, Polity Presse, Cambridge.

Esping-Andersen G., (1994), 'After the golden age, the future of the welfare state in the new global order', mimeo, Occasional paper $n^{\circ} 7$, World Summit for Social Development, UNRISD, Geneva.

Ettner S.L., (1995), 'The impact of parent care on female labor supply decisions', Demography, vol. 32, pp. 63-79.

Ettner S.L., (1996), 'The opportunity costs of elder care', Journal of Human Resources, vol. 31, pp. 189-205. 
Eurostat, (2005), 'EU labour force survey: Principal results 2004', Statistics in Focus, Population and Social Conditions, Eurostat 9/2005.

Gauthier A., (2002), 'Family policies in industrialized countries: is there a convergence?', Population, vol. 57, pp. 447-474.

Gerhard U., Knijn T., Weckwert A., (2005), Working Mothers in Europe. A Comparison of Policies and Practices, Edward Elgar, Cheltenham, UK.

Gordon L., (1990), 'The new feminist scholarship on the welfare state', in L. Gordon (ed), On Women, the State and Welfare, Wisconsin University Press.

Greene W.H., (1998), 'Gender economic courses in liberal arts college: Further results', Journal of Economic Education, vol. 29, pp. 291-300.

Gronau R., (1973), 'The effect of children on housewife's value of time', Journal of Political Economy, vol. 81, pp. S168-S199.

Heckman J. (1974), 'Effects of child-care programs on women's work effort', Journal of Political Economy, vol. 82, pp. S136-S163.

Herlyn I., (2001), 'D'est en ouest, les styles des grands-mères allemandes', in C. AttiasDonfut, M. Segalen, (eds), Le siècle des grands-parents. Une génération phare, ici et ailleurs, Editions Autrement, Paris.

Journal of Labor Economics, (1985), Special issue on trends in women's work, education and family building, vol. $31, \mathrm{n}^{\circ} 1$.

Laferrère A., Wolff F.C., (2006), 'Microeconomic models of family transfers', in S.C. Kolm, J. Mercier Ythier, (eds), Handbook on the Economics of Giving, Reciprocity and Altruism, NorthHolland, Elsevier.

Leira A., (1991), Welfare States and Working Mothers. The Scandinavian Experience, Cambridge University Press, Cambridge.

Leira A., Tobio C., Trifiletti R., (2005), 'Kinship and informal support: Care resources for the first generation of working mothers in Norway, Italy and Spain', in U. Gerhard, T. Knijn, A. Weckwert, (eds), Working Mothers in Europe: A Comparison of Policies and Practices, Edward Elgar, Cheltenham.

Liebfried S., (1992), 'Towards a European welfare state? On integrating poverty regimes into the European Community', in F. Zsuzsa, J.E. Kolberg, (eds.), Social Policy in Changing Europe, Capus Verlag and Westview Press, Frankfurt am Main.

Keane M., Wolpin K., (2001), 'The effect of parental transfers and borrowing constraints on educational attainment', International Economic Review, vol. 42, pp. 1051-1103.

Orloff A.S., (1993), 'Gender and social rights of citizenship, the comparative analysis of gender relations and welfare states', American Sociological Review, vol. 58, pp. 303-328.

Pezzin L.E., Schone B., (1999), 'Intergenerational household formation, female labour supply, and informal caregiving : A bargaining approach', Journal of Human Resources, vol. 34, pp. 475-503.

Pollak R.A., (1988), 'Tied transfers and paternalistic preferences', American Economic Review, vol. 78, pp. 245-250.

Sainsbury D., (1994), Gendering Welfare State, Sage Publications, London.

Sasaki M., (2002), 'The causal effect of family structure on labor force participation among Japanese married women', Journal of Human Resources, vol. 37, pp. 429-440.

Tobio C., (2001), 'En Espagne, la abuela au secours des mères actives', in Attias-Donfut C., Segalen M., (eds), Le siècle des grands-parents. Une génération phare, ici et ailleurs, Editions Autrement, Paris.

Wolff F.C., (2006), 'Parental transfers and the labor supply of children', Journal of Population Economics, forthcoming. 
Table 1. Descriptive statistics by type of transfer

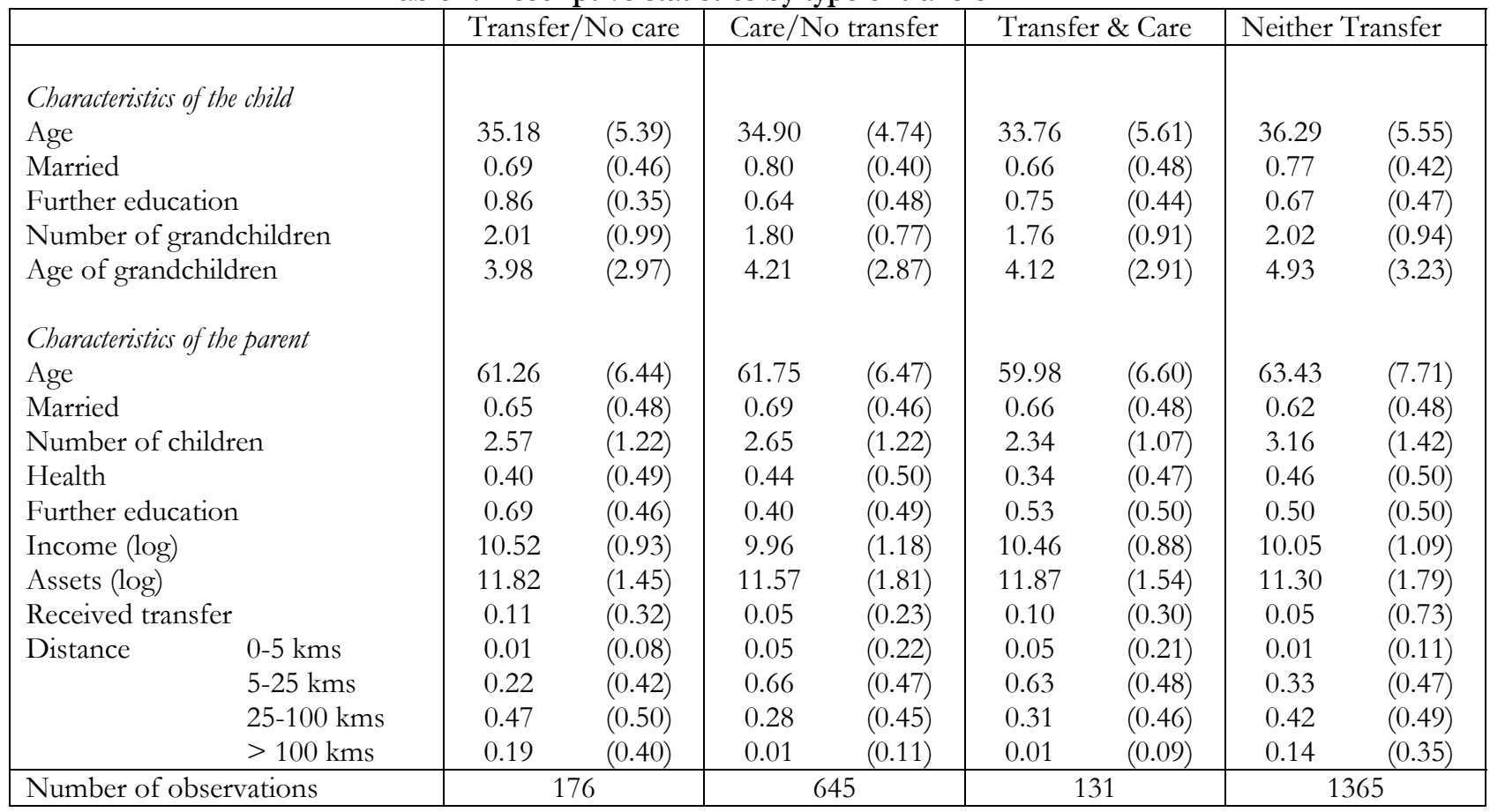

Source: Share release 1, 2003.

The figures in brackets are standard deviations. 
Table 2: Descriptive statistics by employment status

\begin{tabular}{|c|c|c|c|c|c|c|}
\hline & \multicolumn{2}{|c|}{ No work } & \multicolumn{2}{|c|}{ Part time } & \multicolumn{2}{|c|}{ Full time } \\
\hline Characteristics of the child & & & & & & \\
\hline Age & 34.80 & $(5.67)$ & 36.21 & $(5.28)$ & 35.99 & $(4.97)$ \\
\hline Married & 0.79 & $(0.41)$ & 0.76 & $(0.43)$ & 0.75 & $(0.44)$ \\
\hline Further education & 0.56 & $(0.50)$ & 0.69 & $(6.46)$ & 0.85 & $(0.36)$ \\
\hline Number of grandchildren & 2.02 & $(0.96)$ & 1.87 & $(0.84)$ & 1.98 & $(0.90)$ \\
\hline Age of grandchildren & 4.09 & $(3.07)$ & 4.84 & $(3.10)$ & 4.97 & $(3.12)$ \\
\hline Monetary transfer & 0.13 & $(0.33)$ & 0.15 & $(0.36)$ & 0.10 & $(0.31)$ \\
\hline Grandchild care & 0.28 & $(0.45)$ & 0.36 & $(0.48)$ & 0.36 & $(0.48)$ \\
\hline Number of observations & \multicolumn{2}{|c|}{787} & \multicolumn{2}{|c|}{970} & \multicolumn{2}{|c|}{560} \\
\hline
\end{tabular}

Source : Share release 1, 2003.

The figures in brackets are standard deviations 
Table 3. Maximum likelihood estimates of labor force participation, with endogenous grandchild care and monetary transfers

\begin{tabular}{|c|c|c|c|c|c|c|c|}
\hline \multicolumn{2}{|l|}{ Variables } & \multicolumn{2}{|c|}{ Labor supply } & \multicolumn{2}{|c|}{ Grandchild care } & \multicolumn{2}{|c|}{ Monetary transfer } \\
\hline \multirow{2}{*}{\multicolumn{2}{|c|}{ Constant }} & Coef. & S.e. & Coef. & S.e. & Coef. & S.e. \\
\hline & & $-1.506^{* * *}$ & $(0.335)$ & $2.845^{* * *}$ & $(0.517)$ & $-2.541 * * *$ & $(0.731)$ \\
\hline \multicolumn{8}{|c|}{ Characteristics of the child } \\
\hline Age & & $0.042^{* * *}$ & $(0.009)$ & -0.016 & (0.013) & -0.018 & $(0.015)$ \\
\hline Married & & 0.002 & $(0.101)$ & -0.153 & $(0.114)$ & $-0.300 * *$ & $(0.123)$ \\
\hline Number & children & $-0.219 * * *$ & $(0.047)$ & $-0.098^{*}$ & $(0.053)$ & 0.101 & $(0.062)$ \\
\hline Age of $g r$ & Iren & $0.066^{* * *}$ & $(0.015)$ & $-0.053^{* * *}$ & $(0.017)$ & -0.019 & $(0.020)$ \\
\hline Further e & & $0.650 * * *$ & $(0.117)$ & $0.573 * * *$ & $(0.128)$ & $0.306^{*}$ & $(0.168)$ \\
\hline Grandchi & endogenous) & $0.436^{* *}$ & $(2.160)$ & & & & \\
\hline Monetary & (endogenous) & 0.517 & $(1.249)$ & & & & \\
\hline \multicolumn{8}{|c|}{ Characteristics of the parent } \\
\hline Age & & & & $-0.018^{* *}$ & $(0.009)$ & $-0.019 *$ & $(0.011)$ \\
\hline Married & & & & 0.075 & $(0.098)$ & -0.144 & $(0.113)$ \\
\hline Number & & & & $-0.266 * * *$ & $(0.033)$ & $-0.258 * * *$ & $(0.041)$ \\
\hline Health & & & & -0.058 & $(0.093)$ & -0.003 & $(0.111)$ \\
\hline Further e & & & & $-0.475^{* * *}$ & $(0.116)$ & 0.093 & $(0.126)$ \\
\hline Income $(1$ & & & & -0.029 & $(0.030)$ & $0.248^{* * *}$ & $(0.057)$ \\
\hline Assets (lo & & & & $0.025^{*}$ & $(0.015)$ & $0.040^{* *}$ & $(0.020)$ \\
\hline Received & & & & $0.227 * *$ & $(0.099)$ & $0.619 * * *$ & $(0.106)$ \\
\hline Distance & $0-5 \mathrm{kms}$ & & & Ref & & & \\
\hline & $5-25 \mathrm{kms}$ & & & $-0.986 * * *$ & $(0.094)$ & & \\
\hline & $25-100 \mathrm{kms}$ & & & $-2.765^{* * *}$ & $(0.231)$ & & \\
\hline & $>100 \mathrm{kms}$ & & & $-3.669 * * *$ & $(0.544)$ & & \\
\hline \multicolumn{8}{|l|}{ Institutions } \\
\hline Social der & & $0.348^{* *}$ & $(0.161)$ & $-0.811 * * *$ & $(0.169)$ & 0.028 & $(0.185)$ \\
\hline Conserva & & 0.077 & $(0.124)$ & $-0.242 *$ & $(0.144)$ & -0.145 & $(0.167)$ \\
\hline Liberal & & $-0.443^{*}$ & $(0.244)$ & 0.417 & $(0.307)$ & -0.248 & $(0.333)$ \\
\hline \multicolumn{8}{|c|}{ Coefficient of correlation } \\
\hline Labor sup & & 1 & - & -0.019 & $(0.185)$ & -0.472 & $(0.332)$ \\
\hline Grandchi & & & & 1 & - & $0.310^{* * *}$ & $(0.103)$ \\
\hline Monetary & & & & & & 1 & - \\
\hline \multicolumn{2}{|c|}{ Number of observations } & \multicolumn{6}{|c|}{2317} \\
\hline \multicolumn{2}{|c|}{ Log likelihood } & \multicolumn{6}{|c|}{-3346.32} \\
\hline
\end{tabular}

Source: Share release 1, 2003.

Recursive simultaneous model with one Probit equation for labor participation, one Probit equation for grandchild care and one Probit equation for cash transfer, estimated by maximum likelihood. Asymptotic standard errors are in parentheses, and significance levels are respectively $1 \%\left({ }^{* *}\right), 5 \%\left(^{* *}\right)$ and $10 \%\left(^{*}\right)$. 
Table 4. Maximum likelihood estimates of labor force involvement, with endogenous grandchild care and monetary transfers

\begin{tabular}{|c|c|c|c|c|c|c|c|}
\hline \multicolumn{2}{|l|}{ Variables } & \multicolumn{2}{|c|}{ Labor supply } & \multicolumn{2}{|c|}{ Grandchild care } & \multicolumn{2}{|c|}{ Monetary transfer } \\
\hline \multicolumn{2}{|l|}{ Constant } & Coef. & Sign. & Coef. & Sign. & $\begin{array}{c}\text { Coef. } \\
-2.390 * * *\end{array}$ & $\begin{array}{l}\text { Sign. } \\
(0.732)\end{array}$ \\
\hline \multicolumn{2}{|c|}{ Threshold level 1} & $0.796^{* * *}$ & $(0.302)$ & $2.854 * * *$ & $(0.517)$ & & \\
\hline \multicolumn{2}{|c|}{ Threshold level 2} & $1.722^{* * *}$ & $(0.304)$ & & & & \\
\hline \multicolumn{8}{|c|}{ Characteristics of the child } \\
\hline Age & & $0.038^{* * *}$ & $(0.008)$ & -0.016 & $(0.013)$ & -0.018 & $(0.015)$ \\
\hline Married & & 0.014 & $(0.089)$ & -0.154 & $(0.114)$ & $-0.318^{* * *}$ & $(0.123)$ \\
\hline Number & lchildren & $-0.226^{* * *}$ & $(0.043)$ & $-0.097 *$ & $(0.053)$ & 0.097 & $(0.062)$ \\
\hline Age of gr & Aren & $0.043^{* * *}$ & $(0.013)$ & $-0.052^{* * *}$ & $(0.017)$ & -0.019 & $(0.020)$ \\
\hline Further e & & $0.549 * * *$ & $(0.095)$ & $0.568^{* * *}$ & $(0.128)$ & $0.311^{*}$ & $(0.169)$ \\
\hline Grandch & (endogenous) & 0.239 & $(0.176)$ & & & & \\
\hline Monetary & r (endogenous) & 0.093 & $(0.403)$ & & & & \\
\hline \multicolumn{8}{|c|}{ Characteristics of the parent } \\
\hline Age & & & & $-0.018^{* *}$ & $(0.009)$ & $-0.019 *$ & $(0.011)$ \\
\hline Married & & & & 0.078 & $(0.098)$ & -0.143 & $(0.114)$ \\
\hline Number & & & & $-0.266 * * *$ & $(0.033)$ & $-0.259 * * *$ & $(0.041)$ \\
\hline Health & & & & -0.056 & $(0.093)$ & -0.012 & $(0.113)$ \\
\hline Further e & & & & $-0.461 * * *$ & $(0.117)$ & 0.110 & $(0.128)$ \\
\hline Income ( & & & & -0.030 & $(0.030)$ & $0.235^{* * *}$ & $(0.057)$ \\
\hline Assets $(10$ & & & & $0.025^{*}$ & $(0.015)$ & $0.039 * *$ & $(0.020)$ \\
\hline Received & & & & $0.225^{* *}$ & $(0.099)$ & $0.616^{* * *}$ & $(0.107)$ \\
\hline \multirow[t]{4}{*}{ Distance } & $0-5 \mathrm{kms}$ & & & & & & \\
\hline & $5-25 \mathrm{kms}$ & & & $-0.990 * * *$ & $(0.094)$ & & \\
\hline & $25-100 \mathrm{kms}$ & & & $-2.771 * * *$ & $(0.233)$ & & \\
\hline & $>100 \mathrm{kms}$ & & & $-3.651 * * *$ & $(0.534)$ & & \\
\hline \multicolumn{8}{|c|}{ Institutions } \\
\hline \multicolumn{2}{|c|}{ Social democratic } & $0.227 *$ & $(0.133)$ & $-0.813 * * *$ & $(0.169)$ & 0.053 & $(0.187)$ \\
\hline \multicolumn{2}{|c|}{ Conservative } & $-0.459 * * *$ & $(0.104)$ & $-0.248^{*}$ & $(0.144)$ & -0.131 & $(0.169)$ \\
\hline \multicolumn{2}{|l|}{ Liberal } & $-0.986 * * *$ & $(0.242)$ & 0.410 & $(0.305)$ & -0.237 & $(0.333)$ \\
\hline \multicolumn{2}{|c|}{ Coefficient of correlation } & & & & & & \\
\hline \multicolumn{2}{|c|}{ Labor supply } & 1 & - & 0.094 & $(0.163)$ & 0.020 & $(0.317)$ \\
\hline \multicolumn{2}{|c|}{ Grandchild care } & & & 1 & - & $0.312^{* * *}$ & $(0.103)$ \\
\hline \multicolumn{2}{|c|}{ Monetary transfer } & & & & & 1 & - \\
\hline \multicolumn{2}{|c|}{$\begin{array}{l}\text { Number of observations } \\
\text { Log likelihood }\end{array}$} & \multicolumn{6}{|c|}{$\begin{array}{c}2317 \\
-4351.18 \\
\end{array}$} \\
\hline
\end{tabular}

Source: Share release 1, 2003.

Recursive simultaneous model with one Ordered Probit equation for the labor force participation (no job, part time, full time), one Probit equation for grandchild care and one Probit equation for cash transfer, estimated by maximum likelihood. Asymptotic standard errors are in parentheses, and significance levels are respectively $1 \%(* * *), 5 \%(* *)$ and $10 \%(*)$. 
Figure 1. The pattern of grandchildren care in Europe

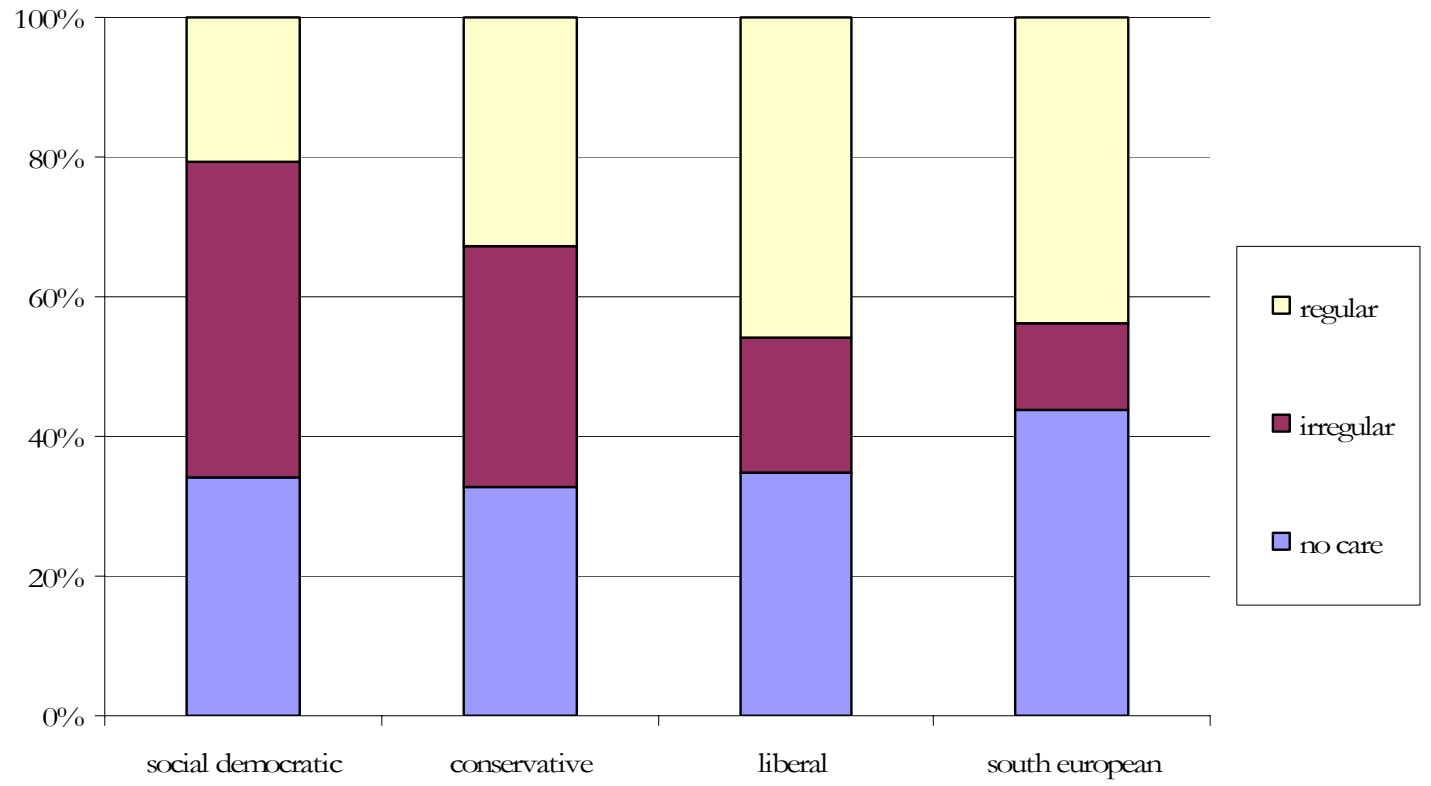

Source : Share release 1, 2003.

Note: Regular care is defined as care provided on daily or weekly basis. The graph is based on the sample of daughters in working age 18-65 who have at least one child of less than 10 years of age, and their elderly mothers. 
Figure 2. The pattern of monetary transfers in Europe

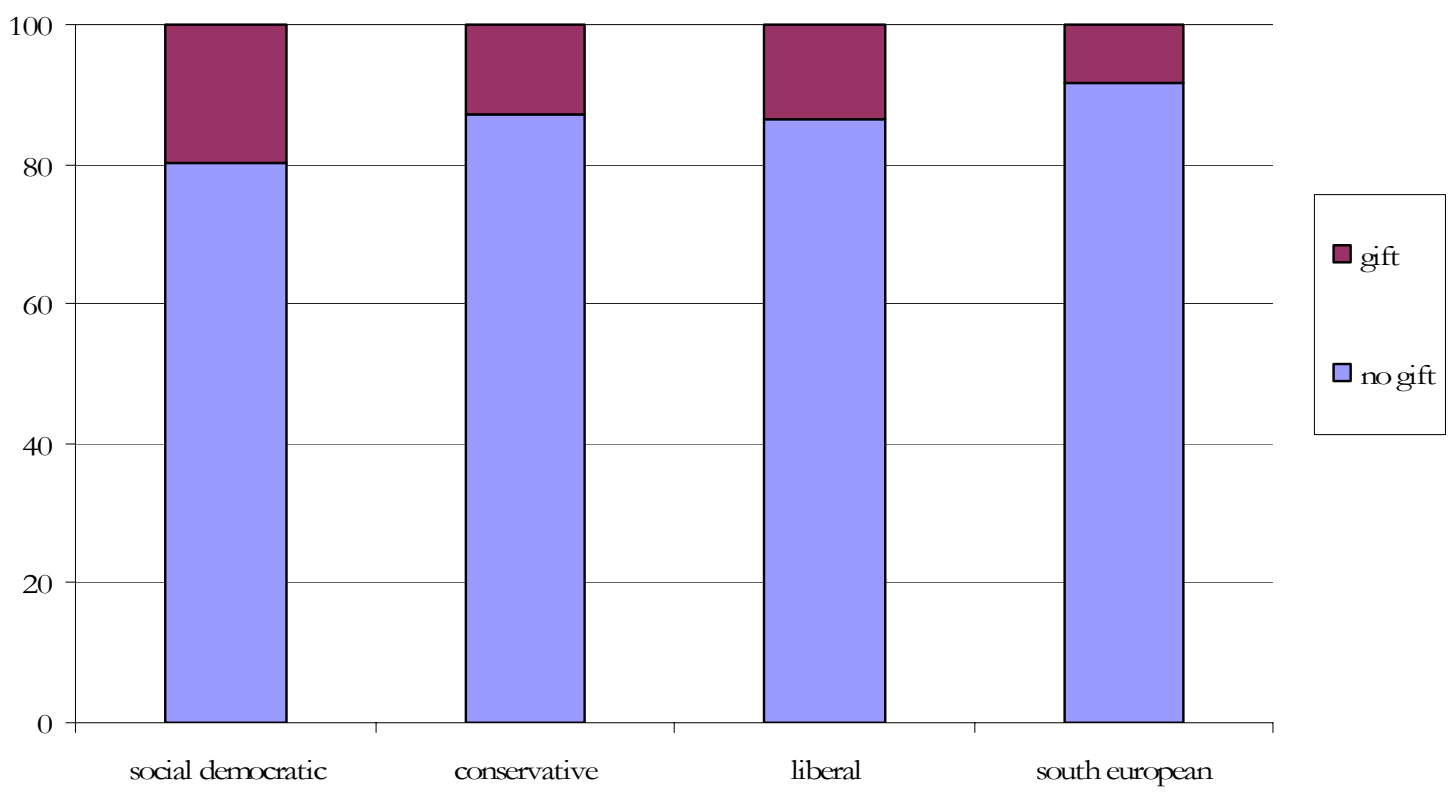

Source : Share release 1, 2003.

Note: The graph is based on the sample of daughters in working age who have at least one child of less than 10 years of age, and their elderly mothers. 
Figure 3. The pattern of labor market participation in Europe

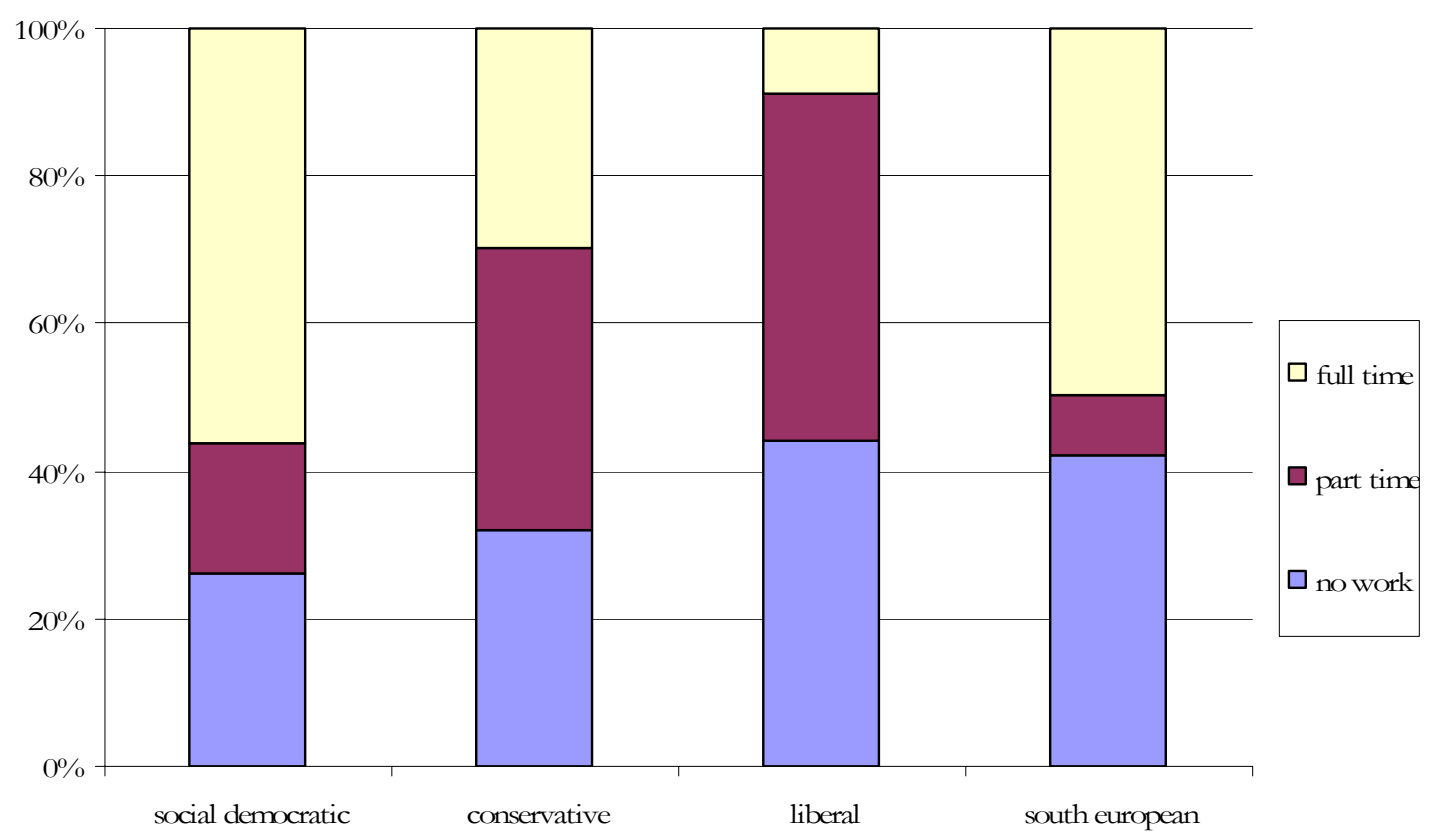

Source: Share release 1, 2003

Note: The graph is based on the sample of daughters in working age 18-65 who have at least one child of less than 10 years of age, and their elderly mothers. 